\title{
Building an automatic system based on IoT technology for monitoring and suppressing dust at the coal processing area
}

\author{
Huy Duy Nguyen ${ }^{1,}$, Duong Thuy Nguyen ${ }^{1}$, Phong Cao Khong ${ }^{1}$, Thinh Van \\ Nguyen ${ }^{1}$, Trong Duc $\mathrm{Vu}^{2}$
}

${ }^{1}$ Hanoi University of Mining and Geology, Hanoi, Vietnam

${ }^{2}$ Mao Khe Coal Company - Vinacomin, Quang Ninh, Vietnam

ARTICLE INFO

Article history:

Received 08 ${ }^{\text {th }}$ Sept. 2021

Revised 20th Dec. 2021

Accepted 12th Jan. 2022

Keywords:

Automatic monitoring,

Diode rectifier,

Insulation resistive,

Unearthed network.

\section{ABSTRACT}

Coal mining is one of the industries that makes many contributions to the national economy. However, this industry also has many negative impacts on the environment, especially in areas: mining, processing, storing and transporting coal. Although coal mining companies use dust suppression methods such as the use of high pressure water jets, or fixed sprinkler or misting systems. However, they do not suppress dust frequently can affect to coal quality due to consume too much water. Besides, coal mines can not real-time monitor dust density in the air, also affect to the health of workers as well as reduces the life of machinery and equipment. Therefore, the design and implementation of an automatic coal dust suppression and monitoring system is essential for coal mining industry in Vietnam. This article proposes an automatic dust suppression system for coal processing area based on IoT technology. The system allows real-time monitoring of dust density, warning when exceeding the allowable threshold, automatically turning on/off the mist spraying system according to the measured dust density to ensure safe working conditions for workers as well as the life of machinery and equipment increased.

Copyright (C) 2022 Hanoi University of Mining and Geology. All rights reserved.

${ }^{*}$ Corresponding author

E - mail: nguyenduyhuy@humg.edu.vn

DOI: 10.46326/JMES.2022.63 (1).09 


\title{
Tạp chí Khoa học Kỹ thuật Mỏ - Địa chất
}

Trang điện tử: http://tapchi.humg.edu.vn

\section{Xây dựng hệ thống giám sát và dập bụi mỏ tự động ứng dụng công nghệ IoT cho các khu chế biến và mỏ than}

\author{
Nguyễn Duy Huy ${ }^{1,{ }^{*}}$, Nguyễn Thùy Dương ${ }^{1}$, Khổng Cao Phong ${ }^{1}$, Nguyễn Văn \\ Thịnh ${ }^{1}$, Vũ Đức Trọng ${ }^{2}$ \\ ${ }^{1}$ Trường Đại học Mỏ - Địa chất, Hà Nội, Việt Nam \\ ${ }^{4}$ Công ty Than Mạo Khê - TKV, Quảng Ninh, Việt Nam
}

\begin{abstract}
THÔNG TIN BÀI BÁO TÓM TẮT

Quá trình:

Nhận bài 08/9/2021

Sưa xong 20/12/2021

Chấp nhận đăng 12/01/2022

Tù̀ khóa:

Chỉnh lưu điôt,

Điện trở cách điện,

Giám sát tự động,

Mạng cách ly.

Ngành công nghiêp khai thác than là môt trong nhũng ngành có nhiều đóng góp cho nền kinh tế quốc dân. Tuy nhiên, ngành công nghiệp này cũng có nhiều tác động tiêu cực đến môi trường, đặc biệt là tại các khu vực: khai thác, chế biến, lưu trũ̃, vận chuyển than. Mặc dù các công ty khai thác than có áp dụng các biên pháp dập bụi nhu: sử dụng máy phun nước áp lực lớn hay các hệ thống phun nước hoặc phun sương cố định nhưng cũng không thể dập bụi thường xuyên vì ảnh hưởng đến chất lượng than do dư thừa nước. Bền cạnh đó việc không giám sát thời gian thực được nồng bụi trong không khí để dập bui kịp thời gây ảnh hưởng đến sức khỏe của người lao động, cũng như làm giảm tuổi thọ của máy móc, thiết bi. Do đó, việc thiết kếvà triển khai hệ thống tự đông giám sát và dập bụi tự động là rất cần thiết. Bài báo này đề xuất hệ thống phun sương dập bư tự động cho khu vực chế biến than trên cơ sở úng dụng công nghể Io T. Hệ thống này cho phép giám sát thời gian thực nồng độ bụi, cảnh báo khi vượt ngương cho phép, tự động bật/tăt hệ thống phun sương dập bụi theo nồng độ bụi đo được nhằm đảm bảo điều kiện làm việc an toàn cho người lao động, góp phần nâng cao tuổi tho cho máy móc, thiết bị.
\end{abstract}

(C) 2022 Trường Đại học Mỏ - Địa chất. Tất cả các quyền được bảo đảm.

\section{Mở đầu}

Ngành công nghiệp khai thác than là một trong những ngành công nghiệp mũi nhọn của Việt Nam, sản phẩm của ngành than là nhiên liệu quan trọng cho nhiều ngành sản xuất khác. Hiện nay và trong

*Tác giả liên hệ

E - mail: nguyenduyhuy@humg.edu.vn

DOI: 10.46326/JMES.2022.63 (1).09 tương lai gần các mỏ khai thácthan hầm lò sẽ đóng vai trò quan trọng trong ngành than Việt Nam. Bụi trong các mỏ than (bụi mỏ) luôn tồn tại và xuất hiện trong các hoạt động khai thác kết hợp với việc thông gió gây nên. Bụi mỏ không chỉ nguy hiểm đối với sức khỏe của người lao động mà còn làm giảm chất lượng, tuổi thọ của các trang thiết bị mỏ, đặc biệt bưi mỏ có thể là tác nhân dẫn tới các vụ cháy nổ bụi than mà hậu quả sẽ vô cùng thảm khốc.

Trong những năm gần đây, hoạt động khai thác, chế biến khoáng sản đã phát triển nhanh về 
quy mô và sản lượng, cũng chính vì thế mà môi trường không khí tại các khu vực khai thác khoáng sản và lân cận thường xuyên bị ô nhiễm do bụi. Do ảnh hưởng của ngành khai thác than nên các khu vực như: Cẩm Phả, Uông Bí, Mạo Khê và một số phường của Hạ Long đang phải sống chung với bụi. Bụi cũng gây ra rất nhiều loại bệnh, đặc biệt là các căn bệnh liên quan đến phổi. Nguồn phát sinh bụi lớn nhất là từ các khâu sàng, chế biến, vận chuyển than,dọc các tuyến đường vận chuyển bằng ô tô. Ngoài ra, bụi còn sinh ra từ các bãi thải chưa dừng đổ thải hoặc những bãi thải đã dừng đổ thải nhưng chưa được cải tạo, phủ thảm thực vật. Theo Báo cáo thống kê của Phòng môi trường, Viện Khoa học Công nghệ mỏ - Vinacomin năm 2017 cho thấy: bụi lơ lửng ở môi trường xung quanh, khu vực sản xuất đều đã vượt $10 \div 20$ lần giá trị cho phép theo tiêu chuẩn quốc tế và tiêu chuẩn Việt Nam. Điều đó rất có hại cho hệ sinh thái môi trường, tới các ngành sản xuất và đặc biệt tới sức khỏe công nhân ngành than.

Hiện nay, ngành công nghệ thông tin đang phát triển rất mạnh mẽ và được ứng dụng rộng rãi trong nhiều lĩnh vực của đời sống, kinh tế xã hội, trong đó có khai thác và chế biến than, bảo vệ môi trường,... Thế giới nói chung, Việt Nam nói riêng đã và đang tích cực chuẩn bị để bước vào cuộc cách mạng công nghiệp 4.0, trong đó Internet vạn vật (Internet of Things - IoT) đóng vai trò chủ đạo. Có thể thấy rằng, xu hướng các máy móc, thiết bị sẽ được kết nối với nhau thông qua mạng Internet, việc theo dõi và điều khiển các máy móc, thiết bị này sẽ trở nên dễ dàng và thuận tiện hơn bao giờ hết,... Đơn giản, IoT là một tập hợp các thiết bị có khả năng kết nối với nhau, với Internet và với thế giới bên ngoài để thực hiện một công việc nào đó. Việc kết nối có thể được thực hiện qua Wifi, Bluetooth, ZigBee, 6LowPan, XBee, Z-Wave, MBus, hồng ngoại, NFC, RFID, Ethernet, mạng viễn thông băng rộng $(3 G, 4 G, 5 G), \ldots$ IoT có thể được ứng dụng vào nhiều lĩnh vực khác nhau, trong đó tập trung vào một số lĩnh vực chính như: quản lí chất thải, quản lí và lập kế hoạch quản lí đô thị, quản lí môi trường, phản hồi trong các tình huống khẩn cấp, mua sắm thông minh, quản lí các thiết bị cá nhân, đồng hồ đo thông minh, tự động hóa ngôi nhà,... Trong tương lai, tất cả các thiết bị trong thế giới thực sẽ tham gia vào mạng IoT, ngành công nghiệp khai thác và chế biến than, khoáng sản cũng không ngoại lệ. Theo Molaei F. và nnk.
(2020), IoT có thể được triển khai ứng dụng trong ngành mỏ vào các công việc như:

(1) Giám sát các hoạt động khai thác nhằm giảm thiểu rủi ro;

(2) Tăng cường an toàn khi khai thác như dự báo sự ổn định của đường lò, sự hư hỏng thiết bị,...;

(3) Các hệ thống giám sát trong khai thác hầm lò như định vị vị trí người lao động, cảnh báo các hiểm họa môi trường như cháy nổ, khí độc, bụi, nước,...;

(4) Tối ưu hóa bằng cách biểu diễn lại dữ liệu hiệu quả, tức là giám sát dữ liệu thời gian thực một cách đồng bộ, cảnh báo khi cần thiết, sử dụng các kỹ thuật khai phá dữ liệu lớn như học máy để dự báo những rủi ro có thể xảy ra nhằm giảm tổn thất, tiết kiệm chi phí khai thác. Các ứng dụng này chủ yếu tập trung vào các khu vực khai thác, nhất là trong các hầm lò nơi có nguy cơ cao về mất an toàn.

Về các phương pháp dập bụi bằng nước phổ biến hiện nay cho các hoạt động khai thác mỏ, Akshatha và Kavyashree (2020) đã tổng hợp các đề xuất của các nhà khoa học về dập bụi bằng nước có kết hợp với cảm biến bụi. Các đề xuất tập trung vào một số giải pháp cụ thể: sử dụng robot cứu hộ để trích xuất thông tin liên quan đến nổ mìn và giám sát vị trí làm việc từ phòng điều khiển bằng cách cảnh báo; phun nước vào không khí để làm giảm nồng độ bụi được sử dụng trong các máy cắt than, gương lò chuẩn bị,... Hệ thống đo trực tiếp lượng bụi sinh ra trong các mỏ than hầm lò. Hệ thống giám sát bụi ngoài trời bằng phương pháp RFWPT để giải quyết vấn đề tiêu thụ nguồn điện. Các cảm biến dựa trên sợi quang đã được thử nghiệm để đo nồng độ bụi trong hoạt động khai thác. Hệ thống giám sát bụi hiệu quả về chi phí có khả năng thu hồi mức bụi mịn tại vị trí cụ thể, gửi cảnh báo nhanh chóng cho người hỗ trợ công tác quản lý ở gần đó. Hệ thống không dây chi phí thấp để đo mật độ bụi vì hệ thống được thiết kế và phát triển với các thiết bị khả dụng đã được thương mại hóa chi phí thấp như cảm biến bụi GP2Y1010AU0F. Hệ thống sử dụng kết quả đánh giá về hình ảnh ô nhiễm bụi than thu được thông qua độ tương phản hình ảnh để loại bỏ bụi bằng cách phun liên hợp khử bụi. Các đề xuất trên không nhắc đến dập bụi bằng hệ thống phun sương công nghệ IoT, đặc biệt là cho khu chế biến và kho than. Ớ các mỏ than vùng Quảng Ninh hiện nay chủ yếu dập bụi bằng phun nước/sương sử 
dụng các máy phun cao áp di động chuyên dụng. Một số mỏ lắp đặt các hệ thống phun sương cố định hoạt động gần như cả ngày lẫn đêm, việc điều khiển hoàn toàn thủ công.

Hiện nay ở Việt Nam, đã có nhiều công ty đang tập trung phát triển giải pháp và sản phẩm công nghệ thông minh với nền tảng IoT. Tuy nhiên, họ chủ yếu tập trung vào các lĩnh vực như: nhà thông minh, nông nghiệp thông minh, nuôi trồng thủy sản thông minh, bãi đỗ xe thông minh, giám sát môi trường, cảnh báo cháy rừng, lũ lụt,... Theo tìm hiểu của nhóm nghiên cứu, ứng dụng của IoT trong ngành khai thác mỏ hiện vẫn chưa được triển khai phổ biến và cần phải được đầu tư nghiên cứu mạnh mẽ hơn nữa. Bài báo này đề xuất mô hình "Hệ thống chống bụi tự động dựa trên công nghệ IoT"'cho các kho và khu chế biến của mỏ than. Hệ thống đề xuất cho phép giám sát các thông số nồng độ bụi do các cảm biến thu thập được, đồng thời đưa ra các cảnh báo và tự động điểu khiển các thiết bị bơm nước, van nước để giảm nồng độ bụi khi nó vượt quá các mức cảnh báo theo quy định.

Việc xây dựng hệ thống dập bụi cho các kho và khu chế biến của mỏ than dựa trên nền tảng của công nghệ thông tin có độ an toàn và tin cậy cao sẽ giúp bảo vệ sức khỏe của người lao động trực tiếp và môi trường xung quanh.

\section{Hệ thống chống bụi tự động dựa trên công nghệ IoT cho các kho và khu chế biến của mỏ than}

\subsection{Quy trình thực hiện}

Để xây dựng hệ thống đề xuất, nhóm nghiên cứu thực hiện theo quy trình sau:

Bước 1: phân tích bài toán, tìm hiểu về bụi, đặc biệt là bụi trong các kho và khu chế biến của mỏ than;

Bước 2: xây dựng sơ đồ khối và phương pháp truyền dữ liệu của hệ thống;

Bước 3: kết nối thiết bị và mô phỏng trên phần mềm mô phỏng;

Bước 4: xây dựng chức năng theo dõi bụi và điều khiển thiết bị;

Bước 5: chạy thử nghiệm và đánh giá.

\subsection{So đồ khối và phương thức truyền dũ liệu của hệ thống}

Sơ đồ khối giúp cho việc lắp đặt hệ thống dễ dàng hơn, hệ thống hoạt động ổn định và cũng dễ bảo trì hơn. Sơ đồ khối của hệ thống được miêu tả như trên Hình 1.

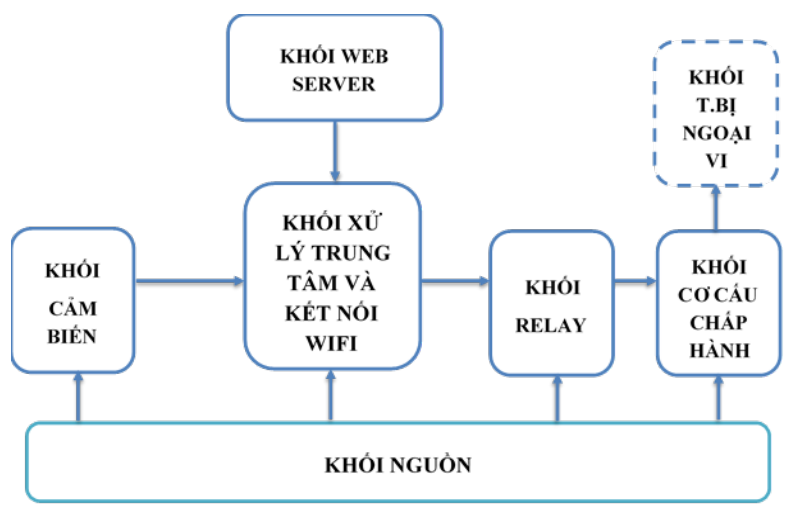

Hình 1. Sơ đồ khối hệ thống đề xuất.

Chức năng cơ bản của từng khối như sau:

Khối nguồn: cung cấp nguồn cho toàn bộ hoạt động của hệ thống bao gồm: khối xử lý trung tâm và kết nối wifi, khối web server, khối cảm biến, khối relay và khối cơ cấu chấp hành. Nguồn có thể là điện áp AC $220 \mathrm{~V}$ hoặc điện áp DC 0-24 V tùy theo thiết bi.

Khối xử lý trung tâm: đây được xem như là trái tim của toàn bộ hệ thống, khối có chức năng tiếp nhận, xử lý mọi tín hiệu ngõ vào thu được từ các cảm biến, các tín hiệu điều khiển từ web, truyền nhận dữ liệu giữa web và phần cứng để xử lý rồi đem những thông số đo được, xử lý được hiển thị lên cho người dùng theo dõi, toàn bộ hoạt động điều khiển của hệ thống được thông qua khối xử lý trung tâm này. Khối này chia thành 2 loại: các khối xử lý trung tâm vệ tinh được kết nối trực tiếp với cảm biến, nhận dữ liệu từ cảm biến và truyền không dây đến khối xử lý trung tâm chủ, sau đó dữ liệu được gửi lên web server.

Khối web server: đây là một khối hoạt động song song, độc lập với khối xử lý trung tâm. Nó có nhiệm vụ lưu trữ và hiển thị dữ liệu thu thập được từ các cảm biến tại khu vực kho và chế biến than cũng như điều khiển các thiết bị trong hệ thống.

Khối cảm biến: có nhiệm vụ thu thập các thông số về bụi (nồng độ bụi PM 2.5) để cung cấp cho khối xử lý trung tâm.

Khối Relay: có nhiệm vụ bật/tắt máy bơm nước. Nó nhận lệnh điều khiển từ khối xử lý trung tâm chủ.

Khối cơ cấu chấp hành: khi các thông số về bụi đọc được từ cảm biến tăng lên hoặc giảm xuống, 
khối xử lý trung tâm sẽ tác động đến khối cơ cấu chấp hành để điều khiển hoạt động của các thiết bị trong khối này.

Khối thiết bị ngoại vi: gồm các thiết bị ngoại vi sử dụng trong hệ thống như máy bơm nước, van nước,,..

Quy trình cập nhật dữ liệu từ cảm biến lên web và ngược lại để điều khiển các thiết bị ngoại vi được cụ thể hoá như trên Hình 2.

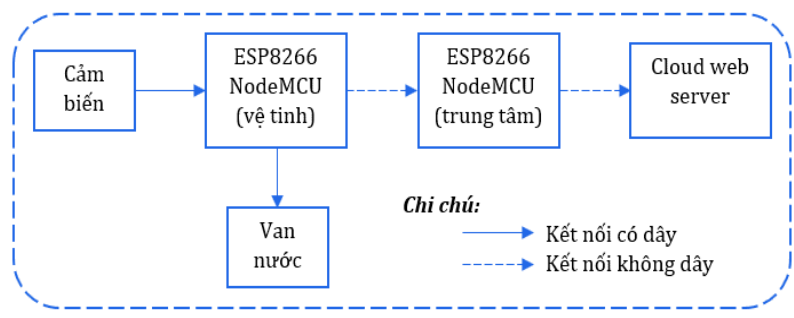

Hình 2. Quy trình cập nhật dữ liệu tù̀ cảm biến lên webapp.

Dữ liệu đo được từ cảm biến sẽ được gửi đến NodeMCU vệ tinh. Do mạch này không có chức năng wifi nên nó tiếp tục được chuyển đến ESP8266 NodeMCU. Mạch này tích hợp chip wifi ESP8266 nên có thể gửi dữ liệu lên web server qua mạng Internet và hiển thị trên webapp. Quy trình truyền dữ liệu từ web đến các thiết bị và cơ cấu chấp hành được thể hiện trên Hình 3.

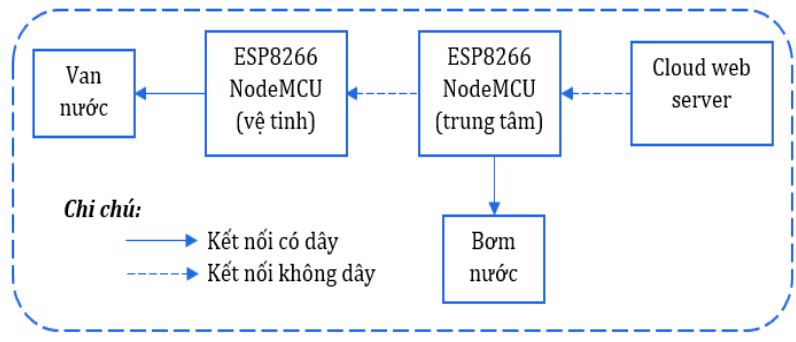

Hình 3. Quy trình truyền dũ liệu từ webapp đến các thiết bị.

Theo chiều ngược lại, những thay đổi trên web app như: đặt lịch bật/tắt máy bơm/van điện từ tự động, bật/tắt máy bơm/van điện từ thủ công sẽ được gửi đến ESP8266 NodeMCU, sau đó là các thiết bị tương ứng (van nước, khởi động từ).

\subsection{So đồ kết nối thiết bi}

Dựa vào những phân tích, đặc biệt là một số hệ thống IoT đã được triển khai thực tế tại Việt Nam, nhóm nghiên cứu đề xuất mô hình triển khai cho hệ thống chống bụi tự động cho các kho và khu chế biến than như hình dưới đây:

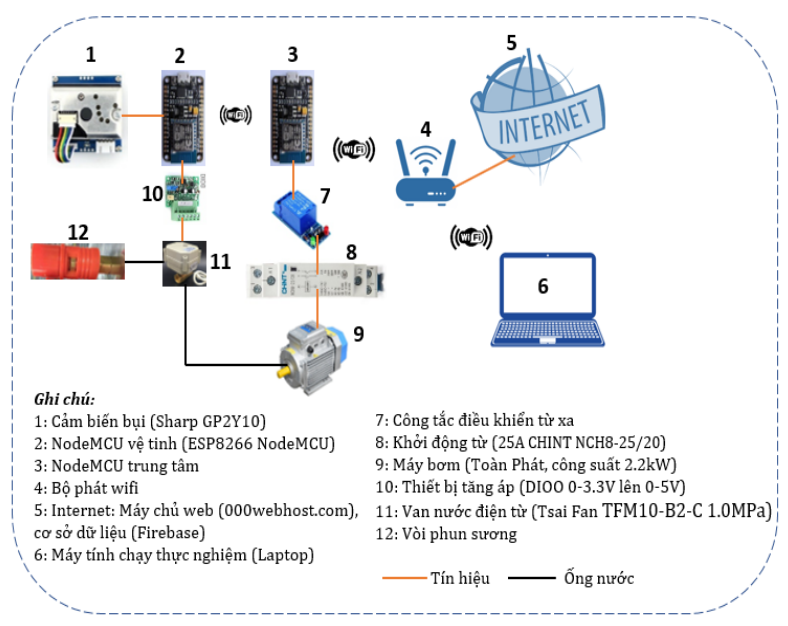

Hình 4. Sơ đồ kết nối các thiết bị của hệ thống.

Tổng hợp các thiết bị được sử dụng gồm:

- Cảm biến bụi: Sharp GP2Y10 (Sharp Corporation, 2006; 2013), được sử dụng để đo nồng độ bụi PM 2.5 .

- Thiết bị kết nối trung tâm: bo mạch ESP8266 NodeMCU.

- Mạch tăng áp DIO0 0-3.3 V lên 0-5 V: tăng điện áp ra 3,3 V từ ESP8266 NodeMCU lên 5 V để làm đầu vào cho van nước điện từ.

- Van nước điện từ: cho phép thay đổi độ mở của van, nghĩa là thay đổi lưu lượng nước chảy qua van phụ thuộc vào nồng độ bụi mà cảm biến đo được nhằm góp phần tiết kiệm nước.

- Khởi động từ (Contactor): do module relay không thể khởi động được các thiết bị có công suất lớn như máy bơm nước nên khởi động từ được sử dụng kết nối với relay để khởi động máy bơm.

- Máy bơm nước: máy bơm nước công nghiệp cỡ vừa/nhỏ để mô phỏng bơm nước dập bụi.

- Access Point/Wireless Router: điểm truy cập Internet không dây, cho phép truyền/ nhận đến/từ ESP8266 NodeMCU.

- Máy chủ đám mây (Cloud Server): hệ thống sử dụng cơ sở dữ liệu Google Firebase (Firebase) và cloud web hosting (000webhost) để đảm bảo hệ thống chạy nhanh, ổn định, dễ nâng cấp và tích hợp các công cụ xử lý dữ liệu lớn về sau.

- Mobile, Laptop: là các thiết bị người dùng sử dụng để giám sát nồng độ bụi cũng như điều khiển thiết bị (bơm nước, van nước) từ xa trên webapp qua Internet.

\subsection{Xây dụng phần mềm theo dõi bụi}

Lập trình theo dõi bụi là bước đầu tiên và khá 
quan trọng của hệ thống đề xuất. Việc lựa chọn thiết bị phù hợp, ngôn ngữ lập trình, môi trường phát triển, thuật toán tối ưu sẽ rất quan trọng để đảm bảo hệ thống hoạt động ổn định và cho kết quả chính xác. Để xây dựng được phần mềm theo dõi bụi trên web cần thực hiện các công việc sau:

- Ghép nối các thiết bị phần cứng liên quan: Cảm biến bụi với ESP8266 NodeMCU (Hình 5).

- Lập trình cho ESP8266 NodeMCU trong Arduino IDE (Arduino).

- Lập trình web app theo dõi bụi theo thời gian thực.

- Xuất bản webapp lên web hosting (Web server).

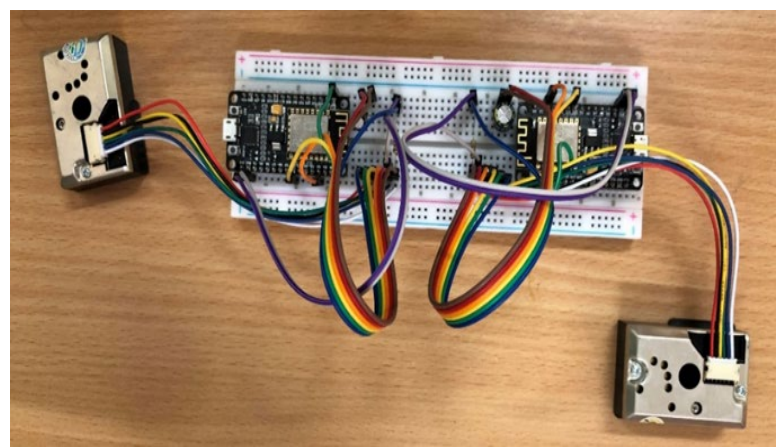

Hình 5. Sơ đồ nối mạch của hệ thống.

\subsubsection{Ghép nối các thiết bị liên quan}

Các thiết bị phần cứng bao gồm: Mạch ESP8266 NodeMCU; Cảm biến bụi Sharp GP2Y10; Điện trở $150 \Omega$; Tụ điện $250 \mu \mathrm{F}$.

\subsubsection{Lập trình cho ESP8266 NodeMCU trong Arduino IDE}

Để lập trình vi điều khiển cho ESP8266 NodeMCU, nhóm tác giả sử dụng Arduino IDE để phát triển. Arduino IDE là môi trường tích hợp phát triển tối ưu cho các thiết bị Arduino với các thư viện hỗ trợ phong phú. Nhóm phát triển 2 chương trình: cho NodeMCU vệ tinh (kết nối trực tiếp với cảm biến) và cho NodeMCU chủ (nhận dữ liệu từ NodeMCU vệ tinh và gửi lên Firebase).

Trong phạm vi nghiên cứu, 2 cảm biến bụi được sử dụng để mô phỏng. Các giá trị về nồng độ bưi được thu thập và cập nhật lên Firbase, sau đó được hiển thị trên webapp. Để xây dựng webapp, có thể sử dụng một số ngôn ngữ phổ biến sau: HTML, PHP, ASP/ASPX, Node.js, Java/JavaScript, Python, Go,... Tuy nhiên, Firebase hỗ trợ 4 ngôn ngư: Node.js, Java/JavaScript, Python, Go. Căn cứ vào đặc điểm của hệ thống và đặc điểm của ngôn ngữ lập trình và khả năng kết nối mạnh mẽ với Firebase, nhóm nghiên cứu lựa chọn JavaScript để xây dựng webapp.

Thực tế khi triển khai có thể có nhiều cảm biến bụi được sử dụng, khi đó tất cả ESP8266 NodeMCU đều phải được kết nối với phần mềm Arduino IDE để ghi chương trình vào bộ nhớ. Do vậy, chương trình chỉ cần lập một lần và sử dụng cho nhiều board khác nhau. Các cảm biến bụi không cần lập trình, chỉ cần kết nối với board là được. Giao diện lập trình cho NodeMCU trong Arduino IDE được thể hiện như trên Hình 6.

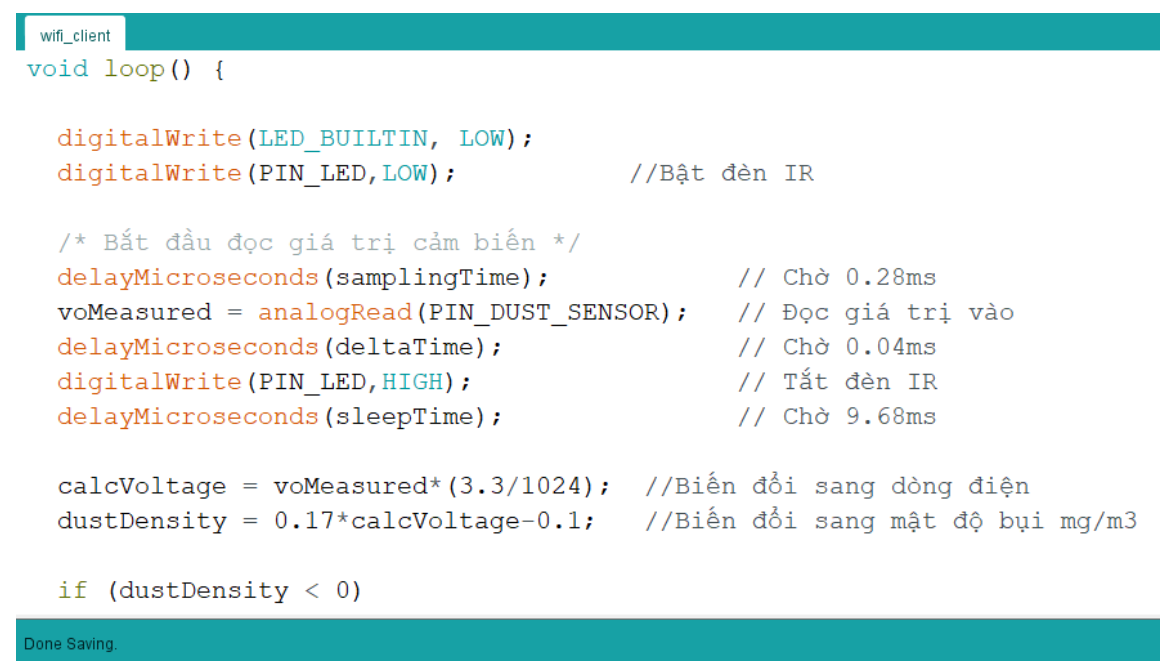

Hình 6. Giao diện Arduino IDE. 
Lập trình cho ESP8266 NodeMCU được chia thành 2 loại do board này đóng 2 vai trò: (1) NodeMCU vệ tinh nhận dữ liệu từ cảm biến, tính toán ra nồng độ bụi rồi gửi cho NodeMCU trung tâm qua kết nối wifi; (2) NodeMCU trung tâm gửi dữ liệu nhận được lên Firebase. Nồng độ bụi (Nb) được NodeMCU vệ tinh tính toán theo công thức (1).

Trong đó:

$$
\mathrm{N}_{\mathrm{b}}=\left(\mathrm{V}_{\mathrm{o}} \times \mathrm{V}_{\mathrm{pd}}\right) / 0.5
$$

$\mathrm{V}_{\mathrm{o}}$ - giá trị điện áp ra của cảm biến sau khi chuyển đổi thành điện áp số.

$\mathrm{V}_{\mathrm{pd}}$ - giá trị điện áp ra của cảm biến:

$$
\mathrm{V}_{\mathrm{pd}}=\mathrm{V}_{\text {ref }} / 1024
$$

$\mathrm{V}_{\text {ref }}$ - giá trị điện áp vào cung cấp nguồn cho cảm biến.

Công thức (1) là do Sharp đề xuất. Tuy nhiên thực tế triển khai, giá trị nồng độ bụi đo được không đúng theo công thức nên các nhà khoa học đề xuất công thức tính như sau:

$$
\mathrm{N}_{\mathrm{b}}=0.17 \times\left(\mathrm{V}_{\mathrm{o}} \times \mathrm{V}_{\mathrm{pd}}\right)-0.1
$$

Trong phạm vi bài báo này, nhóm nghiên cứu sử dụng công thức (3) để tính toán nồng độ bụi.

Khi lập trình cho ESP8266 NodeMCU vệ tinh, ngoài tính toán nồng độ bụi còn phải điều khiển mở/đóng van nước theo nồng độ bụi. Các bước thực hiện như sau:

Thuật toán 1. Điều khiển mở/đóng van nước void $\operatorname{loop}($ ) //Hàm lặp

\{- Bước 1: Tính toán nồng độ bụi $\left(\mathrm{N}_{\mathrm{b}}\right)$ mà cảm biến tương ứng đo được.

- Bước 2: Điều khiển van nước theo nồng độ bụi.

domo $=0 ; / / \%$ độ mở van nước

if $\left(\mathrm{N}_{\mathrm{b}}>\right.$ giới hạn cho phép (>100 $\left.\mu \mathrm{g} / \mathrm{m}^{3}\right)$ )

$\{$ domo $=$ domo $+25 ;$ Mở van domo \%;

//Ghi giá trị xung tương ứng ra chân PWM của NodeMCU\}

else

\{Đóng van; //domo = 0$\}$ loop

Delay (20000); //Dừng 20s\} //Đóng hàm

Trong thuật toán 1 , giá trị giới hạn cho phép về nồng độ bụi được xác định theo quy định của Bộ Tài nguyên và Môi trường (2019). Tổng hợp mức cảnh báo bụi PM 2.5 theo quyết định này được biểu diễn trong Bảng 1.
Bảng 1. Tiêu chuẩn chất lượng không khí theo nồng độ bụi PM 2.5.

\begin{tabular}{|c|c|l|l|}
\hline $\begin{array}{c}\text { Chỉ số chất } \\
\text { lượng } \\
\text { không khí } \\
(\mathrm{AQI})\end{array}$ & $\begin{array}{c}\text { Nồng độ } \\
\text { bụi PM } 2.5 \\
\left(\mu \mathrm{g} / \mathrm{m}^{3}\right)\end{array}$ & \multicolumn{1}{|c|}{$\begin{array}{c}\text { Chất lượng } \\
\text { không khí }\end{array}$} & $\begin{array}{c}\text { Màu } \\
\text { sắc }\end{array}$ \\
\hline $0 \div 50$ & $0 \div 25$ & Tốt & $\begin{array}{l}\text { Xanh } \\
\text { lá cây }\end{array}$ \\
\hline $51 \div 100$ & $26 \div 50$ & Vừa phải & Vàng \\
\hline $101 \div 150$ & $51 \div 80$ & $\begin{array}{l}\text { Không tốt cho } \\
\text { những người } \\
\text { nhạy cảm }\end{array}$ & Cam \\
\hline $151 \div 200$ & $81 \div 150$ & $\begin{array}{l}\text { Có hại cho sức } \\
\text { khỏe }\end{array}$ & Đỏ \\
\hline $201 \div 300$ & $151 \div 250$ & $\begin{array}{l}\text { Rất có hại cho } \\
\text { sức khỏe }\end{array}$ & Tím \\
\hline $301 \div 500$ & $351 \div 500$ & Rất nguy hiểm & Nâu \\
\hline
\end{tabular}

\subsubsection{Lập trình webapp giám sát bụi thò̀ gian thực}

Dũ liệu đo được từ cảm biến đã được tính toán thành nồng độ bụi và được cập nhật lên Firebase. Để lưu trữ được kết quả đo nồng độ bụi trên Firebase cần đăng ký tài khoản, kích hoạt, tạo dự án và ứng dụng trên đó. Nhóm nghiên cứu đã đăng ký, kích hoạt và tạo dự án, ứng dụng. Dưới đây là giao diện của cơ sở dữ liệu của webapp được tạo trên Firebase.

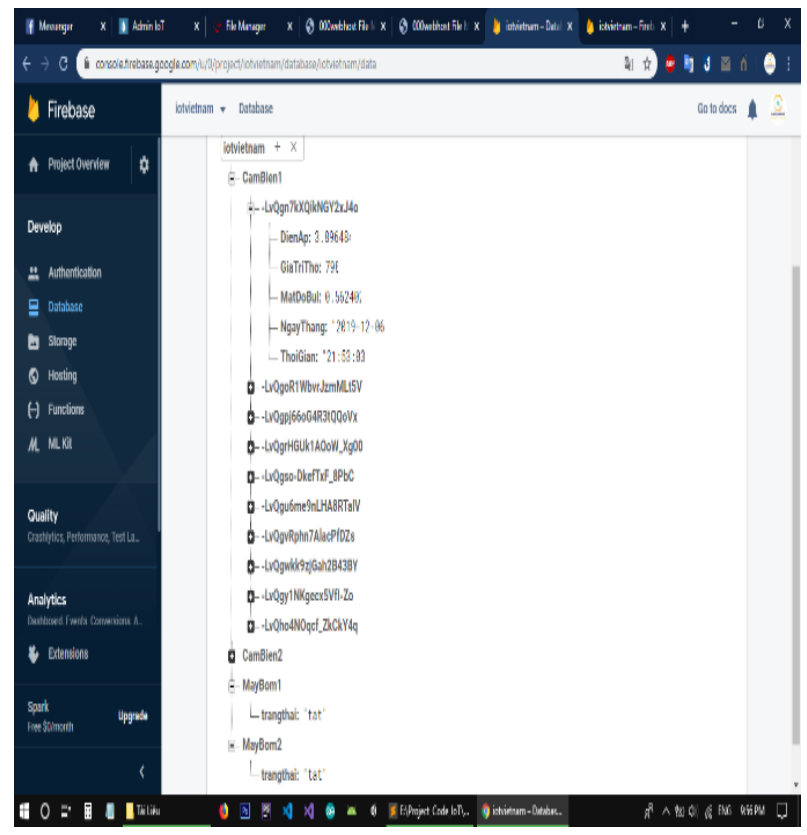

Hình 7. Cơ sở dũ liệu của hệ thống trên Firebase. 
Webapp sẽ kết nối với cơ sở dữ liệu Firebase để lấy thông tin và hiển thị lên giao diện chính. Webapp ngoài nhiệm vụ hiển thị thời gian thực nồng độ bụi và đưa ra cảnh báo khi nồng độ bụi vượt các giá trị ngưỡng $\mathrm{V}_{\mathrm{gh}}$ còn thực hiện các nhiệm vụ khác: tự động bật/tắt máy bơm nước và điều khiển thủ công việc bật/tắt máy bơm hoặc đóng/mở van nước. Việc bật/tắt tự động máy bơm nước nhằm tiết kiệm điện/nước và đảm bảo không phun sương quá nhiều khi không cần thiết làm ảnh hưởng đến chất lượng than được thể hiện trên thuật toán 2.

Thuật toán 2. Bật/tắt tự động máy bơm nước

- Bước 1: Đọc dữ liệu nồng độ bụi của các cảm biến từ Firebase vào mảng $\mathrm{D}_{s}$

- Bước 2: Kiểm tra nồng độ bụi mà mỗi cảm biến đo được.

$\mathrm{kt}=$ false;

for $\left(\mathrm{i}=0 ; \mathrm{i}<\mathrm{N}_{\mathrm{s}} ; \mathrm{i}++\right) / /$ Duyệt tất cả các cảm biến

$$
\begin{aligned}
& \text { if }\left(\mathrm{D}_{\mathrm{s}}[\mathrm{i}]>\mathrm{V}_{\mathrm{gh}}\right) \\
& \quad\{\mathrm{kt}=\text { true; } \\
& \quad \text { Break; }\} \\
& \text { if (!kt \&\& máy bơm đang mở) } \\
& \text { Tắt máy bơm; } \\
& \text { else }
\end{aligned}
$$

Bật máy bơm;

Việc thực hiện bật/tắt thủ công máy bơm hoặc van nước được thực hiện trên webapp. Tín hiệu điều khiển được cập nhật vào firebase, đồng bộ với ESP8266 NodeMCU trung tâm, sau đó chuyển đến khởi động từ để bật/tắt máy bơm hoặc đến NodeMCU vệ tinh để mở/đóng van nước.

\subsubsection{Xuất bản webapp lên web server}

Sau khi lập trình xong webapp thì tiến hành xuất bản webapp, tức là upload toàn bộ nội dung webapp lên web hosting. Web hosting có thể thuê hoặc sử dụng các web hosting miễn phí. Trong phạm vi của đề tài, nhóm nghiên cứu sử dụng dịch vụ web hosting miễn phí (000webhost) để phục vụ cho chạy thử nghiệm hệ thống.

\section{Chạy thử nghiệm và đánh giá}

\begin{tabular}{|c|c|c|c|}
\hline TT & Tên thiết bị & \begin{tabular}{|c|} 
Số \\
lượng
\end{tabular} & Mô tả \\
\hline 1 & $\begin{array}{l}\text { Cảm biến bụi } \\
\text { Sharp GP2Y10 }\end{array}$ & 2 & $\begin{array}{l}\text { Đo nồng độ bụi } \\
\text { PM 2.5, giá trị ra } \\
\text { là điện áp DC }\end{array}$ \\
\hline 2 & $\begin{array}{l}\text { ESP8266 } \\
\text { NodeMCU } \\
\text { v1.0 }\end{array}$ & 3 & $\begin{array}{l}2 \text { thiết bị đóng } \\
\text { vai trò vệ tinh, } 1 \\
\text { đóng vai trò } \\
\text { chủ. Điện áp ra } \\
\text { chân digitap } \\
\text { (PWM) } 0-3.3 \mathrm{~V}\end{array}$ \\
\hline 3 & Module relay & 1 & $\begin{array}{l}\text { Bật/tắt máy } \\
\text { bơm }\end{array}$ \\
\hline 4 & $\begin{array}{l}\text { Khởi động từ } \\
\text { CHINT 20A }\end{array}$ & 1 & $\begin{array}{l}\text { Để khởi động áy } \\
\text { bơm, dòng } 20 \mathrm{~A}\end{array}$ \\
\hline 5 & $\begin{array}{l}\text { Thiết bi tăng } \\
\text { áp DIOO 3.3V } \\
\text { PWM Signal to } \\
0-5 \mathrm{~V} \text { Voltage } \\
\text { Converter } \\
\text { D/A Digital- } \\
\text { Analog PLC } \\
\text { Module 10MA }\end{array}$ & 2 & $\begin{array}{l}\text { Chuyển điện áp } \\
\text { ra 0-3.3VDC của } \\
\text { NodemCU lên } \\
\text { 0-5VDC để cung } \\
\text { cấp cho van } \\
\text { nước điện từ }\end{array}$ \\
\hline 6 & $\begin{array}{l}\text { Van nước điện } \\
\text { từ Tsai Fan } \\
\text { TFM10-B2-C }\end{array}$ & 2 & $\begin{array}{l}\text { Van nước điện } \\
\text { từ điều khiển } \\
\text { được độ mở van } \\
\text { đề tăng/giảm } \\
\text { lưu lượng nước } \\
\text { chảy qua van }\end{array}$ \\
\hline 7 & $\begin{array}{ll}\text { Vòi } & \text { phun } \\
\text { sương } & \end{array}$ & 2 & $\begin{array}{l}\text { Phun sương, có } \\
\text { thể điều chỉnh } \\
\text { được độ mở để } \\
\text { phun xa/gần }\end{array}$ \\
\hline
\end{tabular}

Để chạy thử nghiệm hệ thống, cần lắp đặt thiết bị. Thiết bị sử dụng trong chạy thử nghiệm tại Công ty than Mạo Khê (Hình 8) được liệt kê trong Bảng 2.
Bảng 2. Thiết bị sử dụng chạy thực nghiệm.

Ngoài các thiết bị cơ bản trên, hệ thống còn sử dụng một số thiết bị khác phục vụ chạy thực nghiệm như máy tính, điện thoại thông minh để truy cập vào webapp, Access Point để kết nối Internet qua wifi, ống dẫn nước, bình chứa nước,...

Sau khi cài đặt và chạy thử nghiệm với 2 cảm biến bụi kết hợp với 2 ESP8266 NodeMCU, kết quả theo dõi trên web app cho thấy tín hiệu được gửi lên đều đặn và hiển thị cảnh báo, điều khiển thiết bị đúng theo lập trình như trên Hình 9. Tuy nhiên, việc truyền tải dữ liệu từ cảm biến lên webapp có trễ hơn so với lập trình.

Theo kết quả hiển thị trên Hình 9, tại thời điểm này cảm biến 1 có nồng độ bụi là $144.8 \mu \mathrm{g} / \mathrm{m}^{3}$, cảm biến 2 là $123.28 \mu \mathrm{g} / \mathrm{m}^{3}$. Như vậy theo quy định, cả 

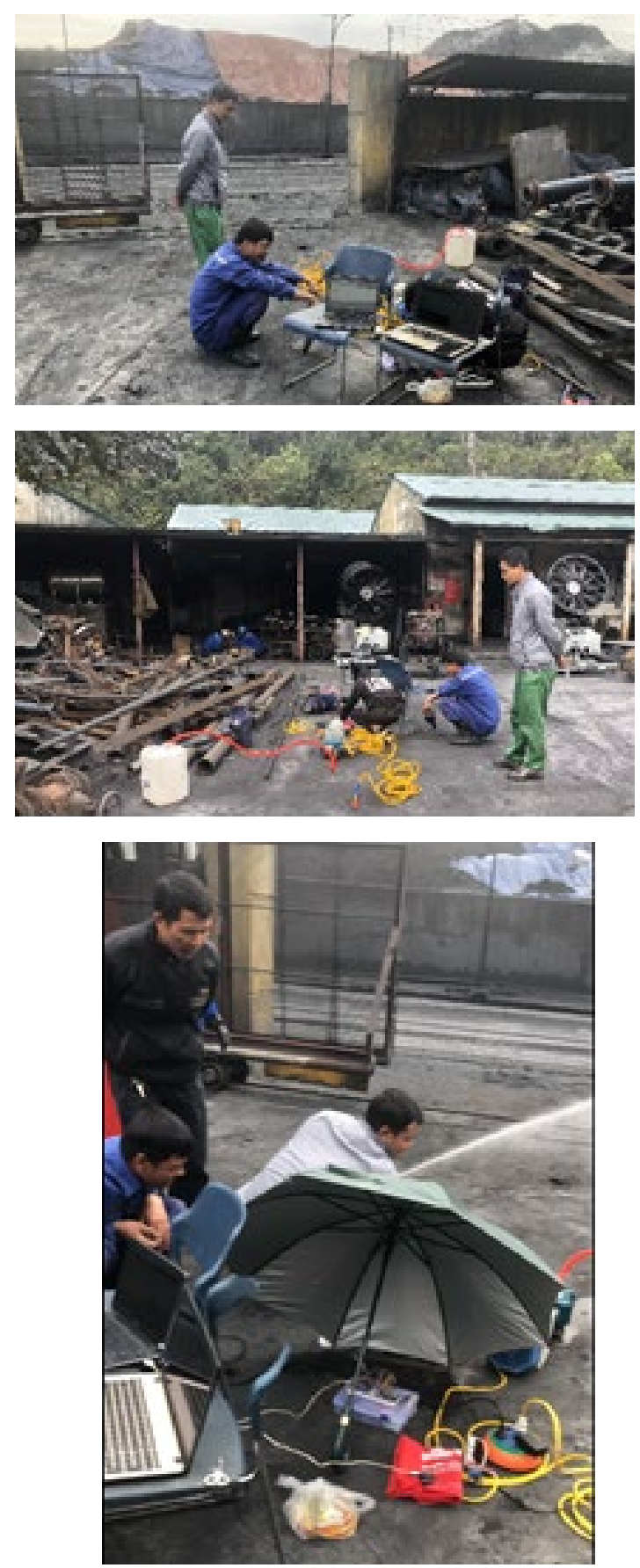

Hình 8. Một số hình ảnh chạy thực nghiệm tại Phân xưởng sàng tuyển than - Công ty than Mao Khê.

hai cảm biến cho biết nồng độ bụi PM 2.5 tại khu vực thực nghiệm đang thuộc mức ô nhiễm nhẹ. Như vậy, cả 2 van nước sẽ ở trạng thái mở (van 1 mở $50 \%$, van 2 mở 25\%), và bơm nước cũng đang ở trạng thái hoạt động. Việc đóng mở van nước cũng như bật/tắt máy bơm là hoàn toàn tự động theo nồng độ bụi đo được. Tuy nhiên, người sử

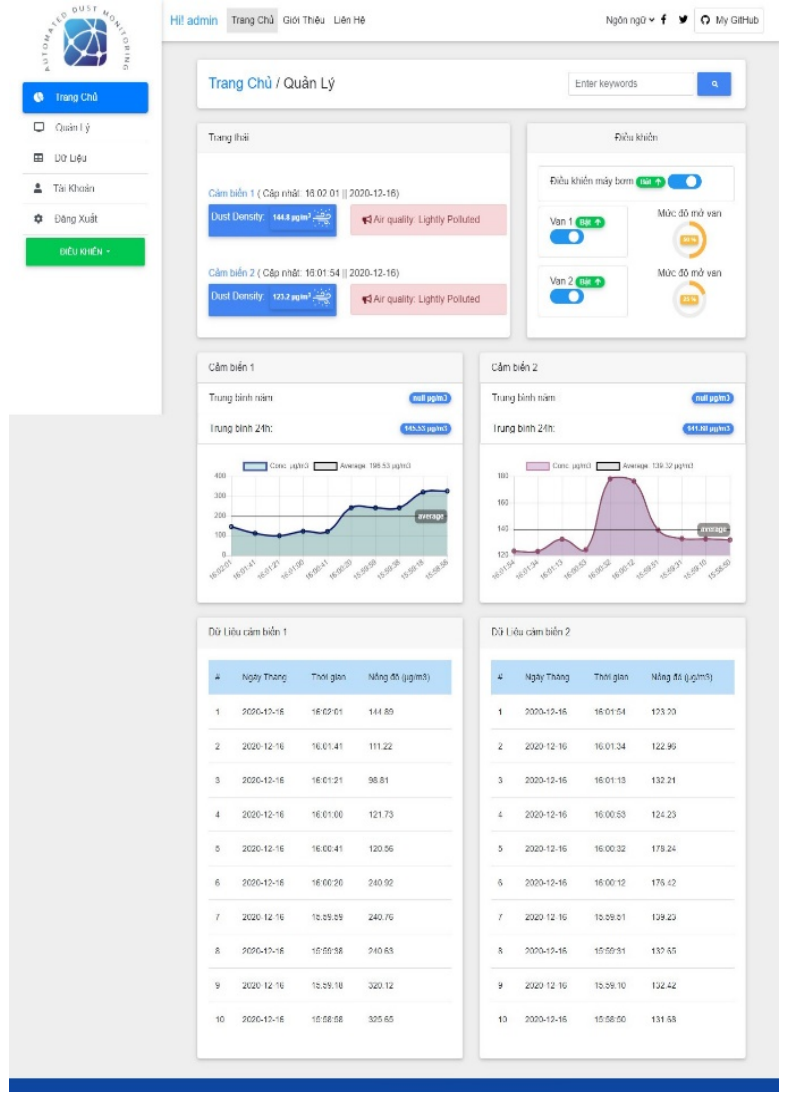

Hình 9. Giao diện chính của webapp.

dụng cũng có thể bật/tắt các thiết bị này thủ công trên webapp.

\section{Kết luận}

Trong bài báo này, nhóm nghiên cứu trình bày các bước xây dựng hệ thống dập bụi tự động ứng dụng công nghệ IoT cho các khu chế biến và kho than. Hệ thống đã được chạy thực nghiệm tại phân xưởng sàng tuyển công ty Than Mạo Khê. Kết quả ban đầu cho thấy hệ thống hoạt động ổn định và cho kết quả khả quan. Trong thời gian tới, nhóm sẽ tiếp tục xây dựng các giải thuật và lập trình các chức năng còn lại của hệ thống như: Thực hiện bật/tắt máy bơm, van nước theo hẹn giờ, căn chỉnh giao diện chính phù hợp hơn trong trường hợp có nhiều cảm biến, van nước để có một hệ thống dập bụi hoàn chỉnh và có thể triển khai trong thực tế.

\section{Lời cảm ơn}

Nhóm tác giả chân thành cảm ơn các nhà khoa học Khoa Công nghệ Thông tin, Khoa Cơ - Điện và Khoa Mỏ Trường Đại học Mỏ - Địa chất đã có những 
góp ý quý báu về chuyên môn, nghiệp vụ; Công ty Than Mạo Khê đã tạo điều kiện thuận lợi để nhóm nghiên cứu thực nghiệm tại Phân xưởng Sàng tuyển than. Bài báo được thực hiện trong khuôn khổ đề tài KHCN cấp Bộ mã số B2019-MDA-07.

\section{Đóng góp của các tác giả}

Nguyễn Duy Huy: xây dựng cấu trúc bài báo, đọc, chỉnh sửa bài báo và lập trình; Nguyễn Thùy Dương: viết bản thảo bài báo; Khổng Cao Phong: lựa chọn thiết bị, xây dựng sơ đồ truyền nhận dữ liệu; Nguyễn Văn Thịnh và Vũ Đức Trọng: kiểm thử hệ thống, lắp đặt hệ thống chạy thực nghiệm tại Công ty Than Mạo Khê, phân tích kết quả và kết luận.

\section{Tài liệu tham khảo}

Arduino. Online: https://www.arduino.cc/

Akshatha, M., \& Kavyashree, M. K. (2020). Survey Paper on Various Methods of Automating the Water System using Dust Sensor to Suppress the Dust in Mining. International Journal of Engineering Research \& Technology (IJERT), 9(5), 1163-1168.
Bộ Tài nguyên và Môi trường. (2019). Hướng dẫn kỹ thuật tính toán và công bố chỉ số chất lượng không khí Việt Nam (VN_AQI). Quyết định số 1459/QĐ-TCMT ngày 12 tháng 11 năm 2019.

Firebase. Online: https://firebase.google.com/

Molaei F., Rahimi E., Siavoshi H., Afrouz S. G., \& Tenorio V., (2020). A comprehensive review on internet of things (IoT) and its implications in the mining industry. American Journal of Engineering and Applied Sciences, 13(3), 499515.

Sharp Corporation. (2006). GP2Y1010AUOF Compact optical dust sensor. Sheet No.: E4A01501EN.

Sharp Corporation. (2013). Application note of Sharp dust sensor GP2Y1010AUOF. Sheet No.: OP13024EN.

000webhost. Free Web Hosting - Host a Website for Free with Cpanel, PHP. Online: https://www.000webhost.com/\#featuretable. 